\title{
Experimental research of motor vehicles on a test bench
}

\author{
Kirill Evseev*, Alexey Dyakov, and Roman Pashkovskiy \\ Bauman Moscow State Technical University, 5/1, 2-ya Baumanskaya street, Moscow, 105005, Russia
}

\begin{abstract}
The article presents one of the possible methods for testing wheeled, tracked movers and support skis. The drag coefficient values of lateral tire deflection are obtained using a test bench and measuring equipment. Atmospheric and road conditions are taken into account. The tests can be carried out at various loads and velocities.
\end{abstract}

\section{Objects and purpose of tests. Test bench}

During tests of wheeled, caterpillar movers and support skis it is required to measure kinematic and power characteristics, as well as performance characteristics [1-3].

Kinematic characteristics include the angular velocity of the wheels or drive rollers of the caterpillar mover.

Power characteristic describes dependence of power from angular velocity of the wheels or drive rollers of the caterpillar mover.

Efficiency characteristics describe dependence of efficiency from angular velocity of the wheels or drive rollers of the caterpillar mover measured at various traction torques.

The objects of testing include all-terrain vehicles and snowmobiles of domestic and foreign production.

The purpose of tests:

- determination of drag coefficients of lateral tire deflection of front and rear axles of allterrain vehicles (ATVs);

- determination of drag coefficients lateral deflection ski and leading snowmobile tracks.

The test objects are all-terrain vehicles:

- with curb weight (mass of the sample prepared for normal operation, filled with fuel and other technical fluids, with tools, without cargo and crew);

- with full weight (mass of the specimen in running order with the driver conducting the tests and the cargo).

Tests are carried out on a special carousel-type test bench (Fig. 1). Test bench consists of: base, rotating support, links, adapter plate, three-dimensional construction of the ATV support.

*Corresponding author: kb_evseev@bmstu.ru 


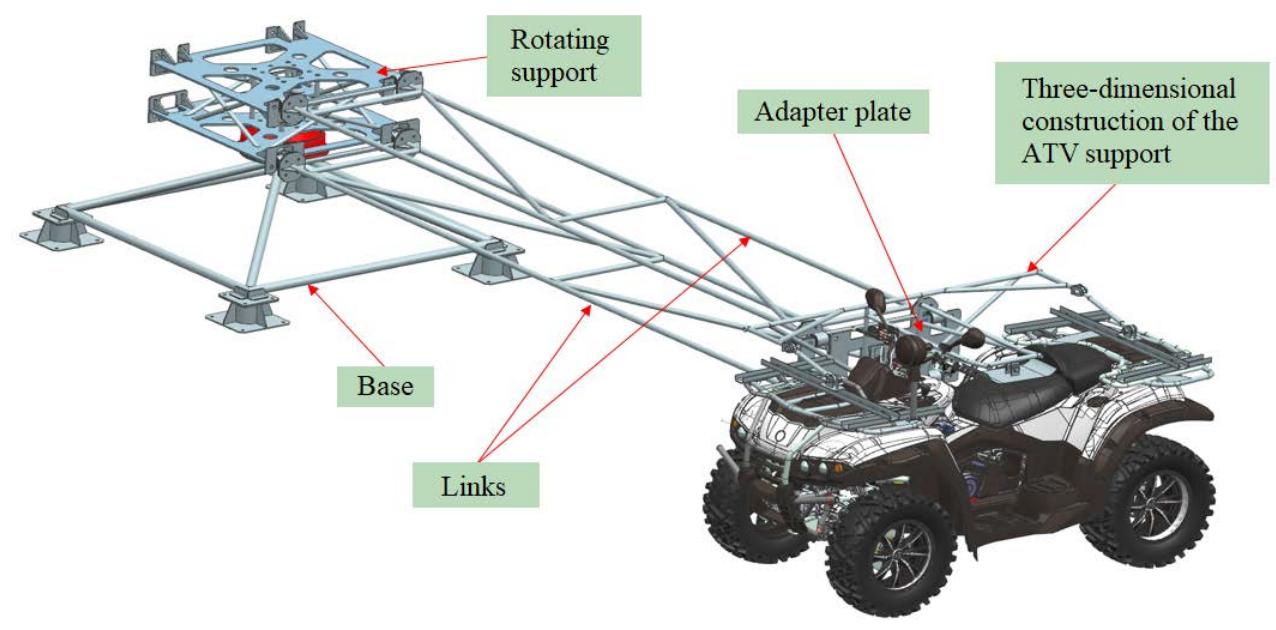

Fig. 1. Test bench general view

Base (Fig. 2) is a welded structure made of tubes, plates, corners and flange. This base is bolted to the welded spacers. Spacers are screwed with anchors to the prepared concrete base.

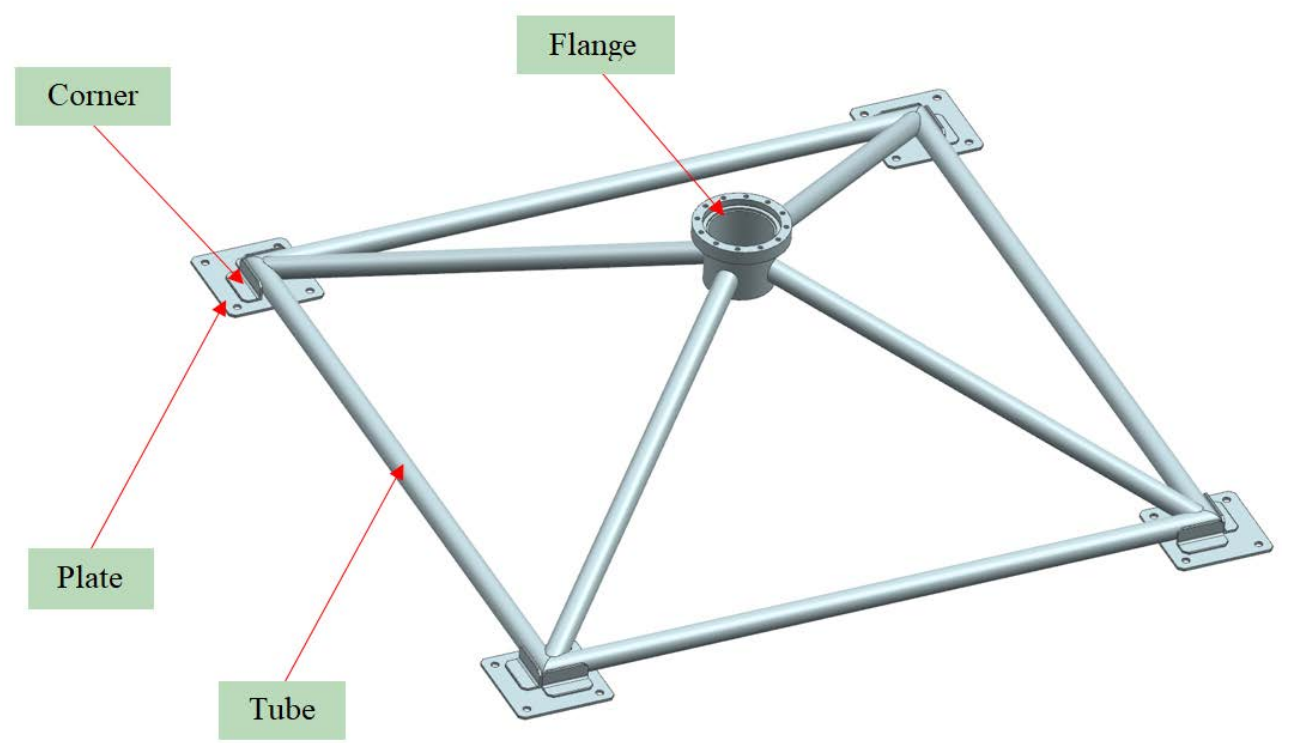

Fig. 2. Base of the test bench

The bearing unit acts as a rotating support, providing movement in a circle. It is screwed to the flange of the base (fig.3). To fix the links on the bearing unit, a welded crosspiece is used. It consists of two steel plates, linked by steel tubes. Corners with holes are welded to the cross-piece. Links are attached to corners. The construction of the crosspiece provides the possibility of installing links on both sides for the simultaneous testing of two all-terrain vehicles. 


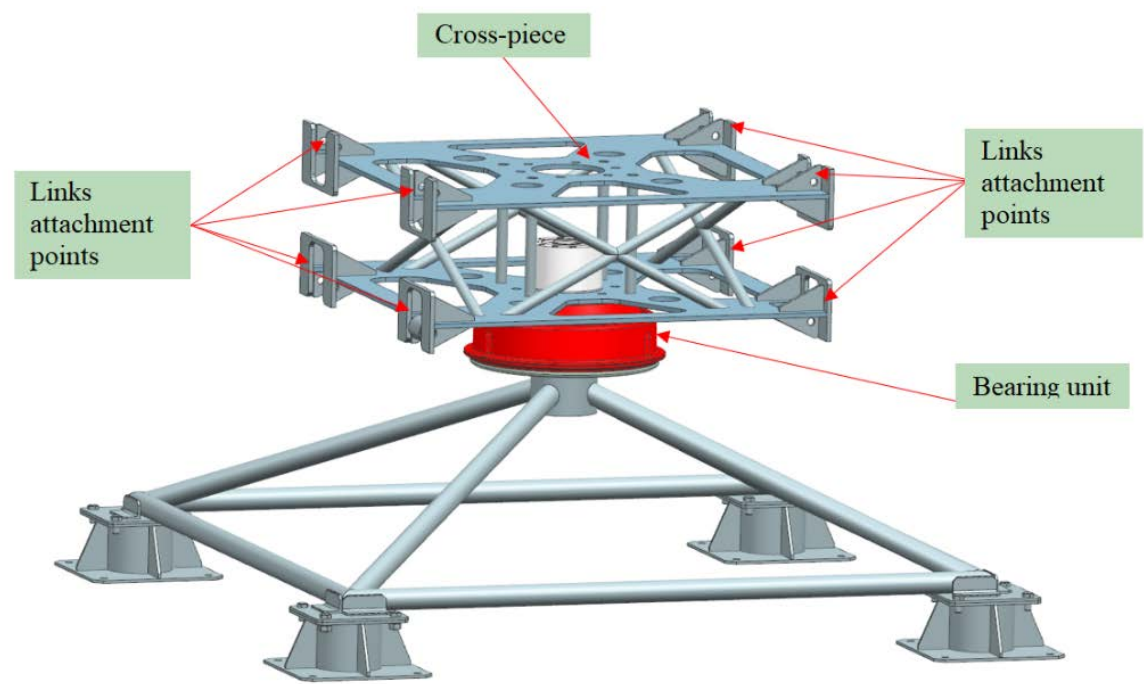

Fig. 3. Base assembled with bearing unit and cross-piece

Welded tube constructions act as links, which are screwed to pivoting bearing with rubber-metal car hinges (fig. 4). This construction provides an opportunity to install links of different lengths and to use of several sequentially fixed links.

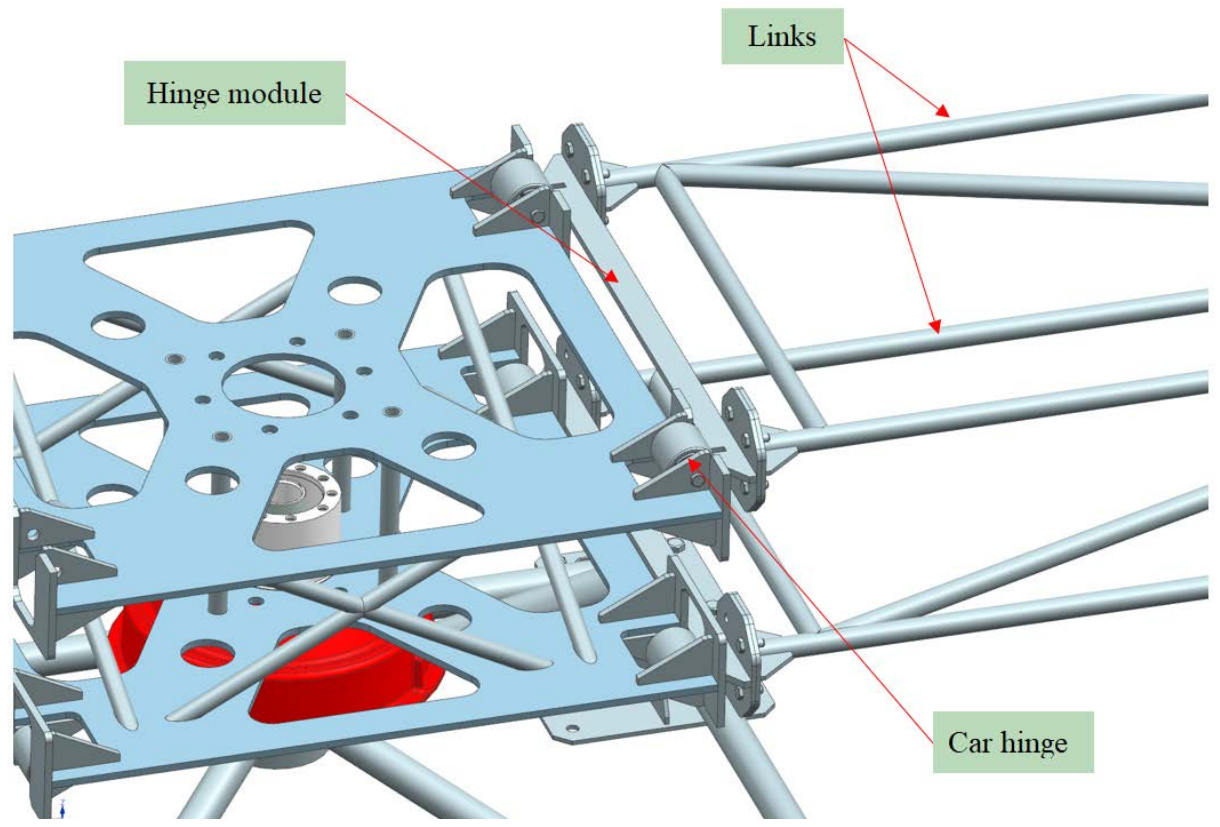

Fig. 4. Links installation

To ensure longitudinal angular vibrations of the ATV, a bearing unit is introduced into the bench construction, which is attached to the links through an adapter plate (fig. 5). On the other side of the spatial construction of the ATV support is attached to the bearing unit, which transfers the vertical load from the test bench weight to the vehicle's seat through the detent, 
thereby replacing the payload. In addition, this construction is screwed to the front and rear ATV's rack using ball rods via clamping bars. This arrangement allows to mount different types of ATVs. From below, the spatial construction of the ATV support is tied with a cable to the footboard of the test vehicle. This eliminates wheel slip along the radius at high velocity.

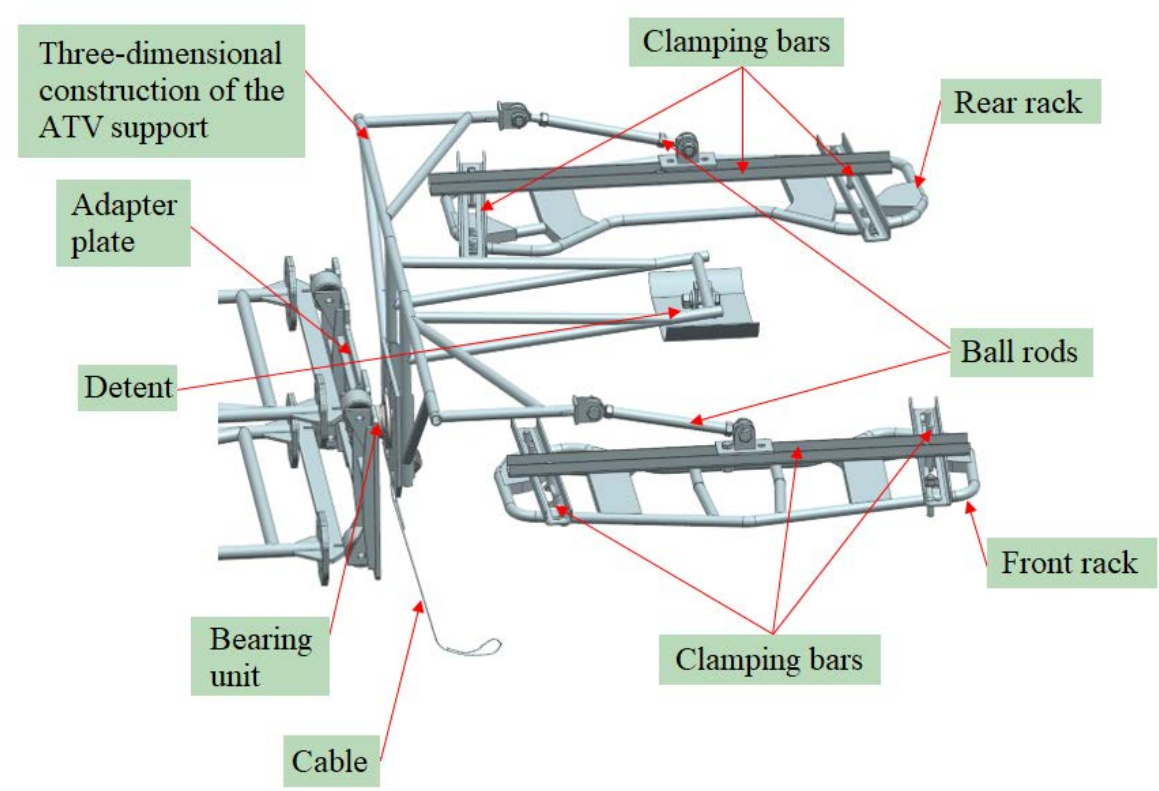

Fig. 5. ATV attachment to the test bench

\section{Management object of tests. Measuring equipment}

The payload (the weight of a person and a cargo) is replaced by an external force. Through the detent, the vertical load from the bench weight is transferred to the ATV seat.

The position of the steering wheel is set using two cables with lanyards attached diagonally to the rear trunk. The steering wheel is turned to the required angle by simultaneously screwing one lanyard and unscrewing the other.

The ATV is remotely controlled via the ESP32 Wi-Fi + Bluetooth WI-FI module and the Arduino Mega 2560 signal processing module. The vehicle's throttle valve is controlled by an LD3Q actuator. It features a compact design that is suitable for a variety of installations and can be used in tight spaces.

The presented bench type for testing wheeled, caterpillar movers and support skis provides for a number of research tests of various models of snowmobiles and ATVs.

List of measuring equipment:

1. Racelogic Vbox data logger and VBOXTools software

They are used to measure the velocity and position of a moving vehicle. Based on signals from GPS receivers, the devices record information about measurements of velocity, distance, acceleration, and braking distance.

2. Racelogic camcorders

They are used for fixing parameters, registration and video recording of events in a dedicated area for tracking. They allow for continuous monitoring and recording of the situation in the surveillance area, if necessary, view the recorded images and video. 
3. RM44SC rotary encoder

RM44 is an encoder designed for integration on motors or other devices for shaft position detection and angular velocity measurement.

4. Torque sensor M40

It measures the torque at the joint that connects the test bench and the ATV.

\section{Testing program and methods}

To achieve the goal - determination the drag coefficient of lateral tire deflection were developed testing program and methods. In addition, the use of a test bench makes it possible to assess the traction-velocity and energy characteristics of single movers.

\subsection{Test procedure}

The tests should be carried out during daylight hours. Experiments are not allowed with a sharp change in the physical and mechanical properties of the support base, in conditions of precipitation (fog, rain, etc.) and at a wind speed of more than $3 \mathrm{~m} / \mathrm{s}$, with gusts of more than $5 \mathrm{~m} / \mathrm{s}$.

Samples intended for testing should be technically sound, adjusted, run in, staffed, filled with fuel and oil in accordance with the operation manual. Wheels should not have mechanical damage; permissible wear is not more than $10 \%$.

Immediately before testing begins, the vehicle should be warmed up by driving non-stop for 5 to 10 minutes at a speed of 20 to $40 \mathrm{~km} / \mathrm{h}$ with periodic braking.

The ATV frame must be securely attached to the load-bearing structure of the bench; the controlled movers must be fixed in a position corresponding to the direction of turn and the turning radius.

An ATV for experimental research should be tested with different loads:

- curb weight and driver weight;

- curb weight, weight of the driver and passenger.

The ATV should be driven at a constant speed of $5 \mathrm{~km} / \mathrm{h}$.

The vehicle should be driven no more than three full circles.

Registration of the measured parameters begins automatically from the moment of starting and ends within 3 seconds after a full stop.

\subsection{Recording of motion parameters}

Instrumentation should record (fig.6):

- ATV angular velocity $\omega_{z}$ about the vertical axis;

- rotation angles $\theta_{\text {left }}$ and $\theta_{\text {right }}$ (respectively, left and right) of the front steered wheels relatively to the middle position;

- lateral force $F_{y}$ acting on the ATV frame from the side of the ATV attachment system to the test bench load structure;

- lateral forces on the wheels of the front axle $F_{11 y}$ and $F_{12 y}$;

- lateral forces on the wheels of the rear axle $F_{21 y}$ and $F_{22 y}$;

- torque $M_{z}$ acting on the ATV frame from the its attachment system to the test bench load structure. 


\subsection{Processing of test results}

On the oscillograms of the measured values $\omega_{z}, F_{y}, M_{z}$, it is necessary to select the recording area with the steady-state values of these parameters. These values must be selected for subsequent calculations.

The difference between the slip angles

$$
\Delta=\delta_{2}-\delta_{1}
$$

for the wheels of the rear and front axles:

$$
\Delta=\delta_{2}-\delta_{1}=\frac{\left(F_{y}+\frac{M_{z}}{L}\right) g L}{G_{a}\left(\omega_{z}\left[R_{\mathrm{cr}}+B\right]\right)^{2}}-\sin \left(\frac{\theta_{\text {left }}+\theta_{\text {right }}}{2}\right)
$$

$L$-ATV wheelbase; $G_{a}$ - vehicle weight; $R_{c m}$ - the distance from the vertical axis of rotation to attachment point of the ATV frame to the load-bearing structure of the bench; $B$ - the distance from attachment point of the ATV frame to the load-bearing structure of the bench to the longitudinal axis of symmetry of the ATV.

Drag coefficients $K_{1}$ and $K_{2}$ of lateral tire deflection of the front and rear axles, respectively, are determined by solving the system of equations:

$$
\left\{\begin{array}{c}
\frac{G_{a}}{F_{y}+\frac{M_{Z}}{L}}\left[\Delta+\sin \left(\frac{\theta_{\text {left }}+\theta_{\text {right }}}{2}\right)\right]=\frac{2 G_{2}}{K_{2}}-\frac{2 G_{1}}{K_{1}} \\
\Delta+\sin \left(\frac{\theta_{\text {left }}+\theta_{\text {right }}}{2}\right)=\frac{2\left(F_{21}+F_{22}\right)}{K_{2}}-\frac{2\left(F_{11} \cos \theta_{\text {left }}+F_{12} \cos \theta_{\text {right }}\right)}{K_{1}}
\end{array}\right.
$$

$G_{1}, G_{2}$ - weight on the front and rear vehicle axles, respectively $[4,5,6]$.

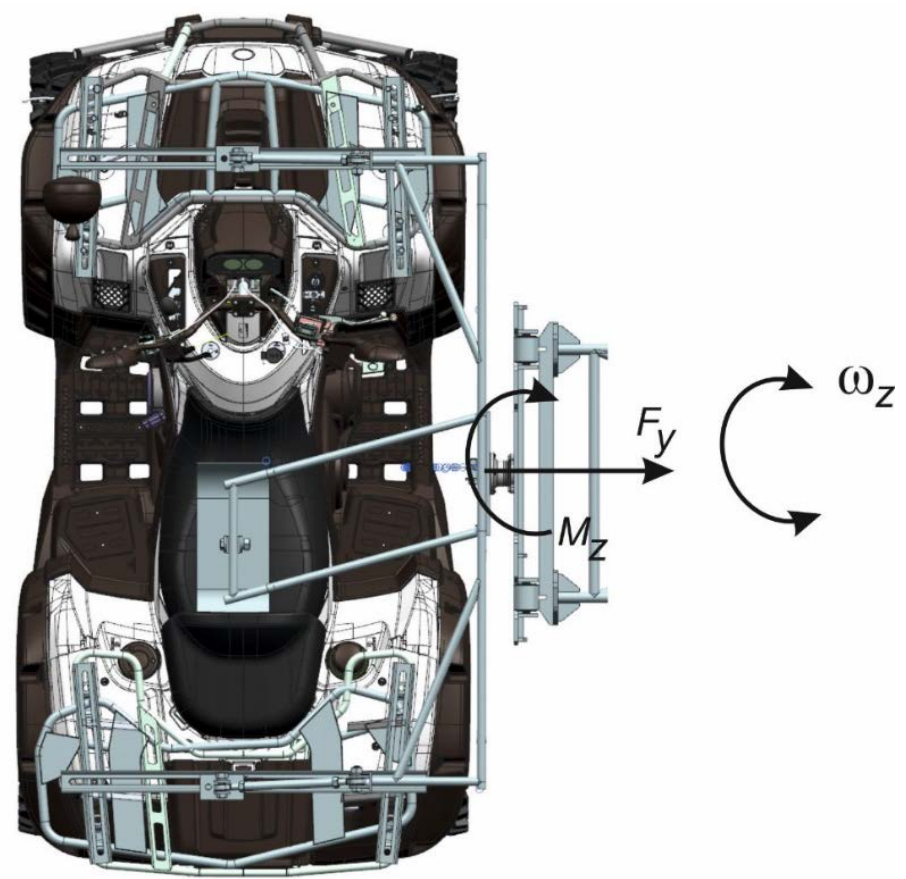

Fig. 6. Measured quantities 


\subsection{Test conditions}

Tests are carried out on a test bench:

- for ATVs on a flat asphalt concrete platform;

- for snowmobiles on a flat area covered with a snow cover no more than $5 \mathrm{~cm}$ deep.

Tests can be carried out year-round, depending on the purpose.

Tests should be carried out in calm weather at an ambient temperature above $-15^{\circ} \mathrm{C}$ and no more than $0^{\circ} \mathrm{C}$ in winter, above $0^{\circ} \mathrm{C}$ and not more than $+20^{\circ} \mathrm{C}$ in summer.

The tests should be carried out following climatic conditions:

- ambient temperature, ${ }^{\circ} \mathrm{C} \quad$ from -15 to +20

- relative air humidity, \% from 45 to 90

- atmospheric pressure, $\mathrm{mm} \mathrm{Hg} \quad$ from 630 to 800

The operating time of the test object before start of test should be at least 24 hours and should be confirmed by a list of previously conducted tests with the operating time recording.

During tests work is carried out in the scope of a control examination of the test object and, if necessary, its current maintenance.

\section{Conclusion}

The developed test bench provides experimentally measure of the drag coefficient of lateral ATV tire deflection. This test bench can be easily assembled and disassembled. The developed program and methods of experimental research provide correct results on the assessment of the drag coefficient of lateral tire deflection. It was established that need to ensure the simultaneous fixing of the kinematic, power characteristics and efficiency characteristics to determine the parameters. This test bench can be used for other purposes as well. For example, for testing electromechanical ATV transmissions. [7-10].

\section{References}

1. GOST 52008-2003 Four wheel all-terrain vehicles. General technical requirements.

2. GOST 50944-2011 Snowmobiles. Technical requirements and test methods.

3. GOST 32571-2013 All Terrain Vehicles (ATVs - Quads) - Safety requirements and test methods.

4. Mathematical models of the movement of wheeled vehicles / Vlakhova A. V. - M.; Izhevsk: Institute of Computer Research, 2014.-- 147 p. - Bibliography: p. 141-147. ISBN 978-5-4344-0230-9

5. Theoretical foundations of increasing the stability and controllability of wheeled vehicles based on methods of fuzzy logic / Zhileikin M.M. - M.: Publishing house of MGTU im. N.E. Bauman, 2016.-- 238 p. : ill. - Bibliography: p. 235-238. - ISBN 9785-7038-4278-2.

6. Klubnichkin V., Dyakov A., Klubnichkin E., Zakharov A., Vakhidov U., Suchenina A., and Basmanov I. 2019. Experimental evaluation of stability and controllability of domestic and foreign made utility terrain vehicles. J. Phys.: Conf. Ser. Vol. 1177 012045 .

7. Ilyushin D., Salikin Y., Shekhovtsov V., Diakov A. S., Evseev K. B. Special aspects of the test of ATV equipped with the electronic engine management system Continental M3C on a dynamometer test bench. J. Phys.: Conf. Ser. Vol. 820012011. 
8. Diakov A. S., Salykin E. A., Potapov P. F. 2020. Hub dynamometric stand test features of the ATV engine and continuously variable transmission unit. J. Phys.: Conf. Ser. Vol. 709044002.

9. Lyashenko M., Potapov P., Dolotov A., Diakov A. S., Evseev K. B., Zverev A. V. Analysis of ATV transmission operation according to the results of tests on a dynamometer test bench. J. Phys.: Conf. Ser. Vol. 820012018.

10. Klubnichkin V. E., Diakov A. S., Klubnichkin E. E., Zakharov A. Y., Vakhidov U. Sh., Suchenina A. S., Basmanov I. V. 2019. Experimental evaluation of speed and brake properties of domestic and foreign made utility terrain vehicles. J. Phys.: Conf. Ser. Vol. 1177012048 